\title{
Clinicopathologic Significance of BRAF Mutation and Extracellular Signal Regulated Kinase 1/2 Expression in Patients With a Colorectal Adenocarcinoma
}

\author{
Hyung Ook Kim, Beom Gyu Kim¹, Seong Jae Cha ${ }^{1}$, Yong Gum Park ${ }^{1}$, Tae Jin Lee ${ }^{2}$ \\ Department of Surgery, Kangbuk Samsung Hospital, Sungkyunkwan University School of Medicine, Seoul; Departments of ${ }^{1}$ Surgery and \\ ${ }^{2}$ Pathology, Chung-Ang University College of Medicine, Seoul, Korea
}

Purpose: BRAF mutation and expression of extracellular signal regulated kinase (ERK) are linked with colorectal carcinogenesis through the serrated pathway. BRAF and ERK1/2 play important roles in the activation of mitogen-activated protein (MAP) kinase signaling pathways. The present study investigated the clinicopathologic outcomes of BRAF mutation and ERK1/2 expression in patients with colorectal cancer (CRC) and the possibility of using them as prognostic indicators. Methods: Dual-priming oligonucleotide-based multiplex polymerase chain reaction for $B R A F^{V 600 \mathrm{E}}$ mutation and immunohistochemical analysis of ERK1/2 were performed using 65 formalin-fixed, paraffin-embedded samples from patients with CRC. We analyzed the dependences of the clinicopathologic features on BRAF mutation and ERK1/2 expression.

Results: Out of 65 samples from CRC patients, BRAF mutation was detected in 3 (4.6\%). The 3 patients with BRAF mutation presented with T3 CRC with lymph node metastasis (stage III) showing moderately or poorly differentiated histology. ERK1 and ERK2 were positively detected in $73.8 \%$ and $15.4 \%$ of the patients with CRC, respectively. ERK1 expression was significantly correlated with lymph node metastasis $(P=0.049)$. ERK2 expression was significantly correlated with tumor emboli $(\mathrm{P}<0.05)$, tumor invasion $(\mathrm{P}=0.035)$, lymph node metastasis $(\mathrm{P}=0.017)$, and stage $(\mathrm{P}=0.02)$.

Conclusion: BRAF mutation and ERK1/2 expression may be associated with advanced or more aggressive CRC. These molecular markers might play prognostic roles in CRC developed through the serrated pathway.

Keywords: BRAF; ERK1; ERK2; Colorectal neoplasms; Adenocarcinoma

\section{INTRODUCTION}

The development of colorectal cancer (CRC) is a multistep process that occurs because of the accumulation of several genetic alterations, which are associated with oncogenes and tumor suppressor genes, as well as genes involved in DNA damage recognition and repair. These genetic changes lead to CRC carcinogenesis

Received: November 25, 2014 - Accepted: January 3, 2015

Correspondence to: Beom Gyu Kim, M.D.

Department of Surgery, Chung-Ang University Hospital, 102 Heukseok-ro,

Dongjak-gu, Seoul 156-755, Korea

Tel: +82-2-6299-1545, Fax: +82-2-824-7869

E-mail:kimbg0526@paran.com

(C) 2015 The Korean Society of Coloproctology

This is an open-access article distributed under the terms of the Creative Commons Attribution NonCommercial License (http://creativecommons.org/licenses/by-nc/3.0) which permits unrestricted noncommercial use, distribution, and reproduction in any medium, provided the original work is properly cited. through various morphological stages.

There are two traditional pathways in regard to CRC carcinogenesis. One is chromosomal instability, which leads to changes in the number or the structure in proto-oncogenes and tumor suppressor genes $[1,2]$. The other is DNA replication errors caused by mismatch repair gene defects $[3,4]$. However, in addition to these, recently, BRAF mutation and hypermethylation of DNA cytosineguanine base pairs ( $\mathrm{CpG}$ islands), namely, an epigenetic alteration such as $\mathrm{CpG}$ island methylator phenotype (CIMP), have been found to play roles in CRC carcinogenesis [5].

Clinicopathologic differences are caused by different genetic or epigenetic alterations in CRC. About $70 \%-80 \%$ of CRC develops through the adenoma-carcinoma sequence. The remaining 20\%$30 \%$ of CRC develops through the serrated pathway, which could account for CRC without a prodromal change such as adenoma or with other prodromal lesions [6]. The serrated pathway is based on serrated polyps, which are classified into dysplastic and non- 
dysplastic polyps. Nondysplastic serrated polyps comprise hyperplastic polyps and sessile serrated adenoma/polyps. Dysplastic serrated polyps include traditional serrated adenomas and sessile serrated adenoma/polyps with dysplasia $[7,8]$. These serrated polyps are associated with several somatic molecular alterations previously reported as BRAF mutations, KRAS mutations, MLH1 methylation, MGMT (O6-methylguanine-methyltransferase) methylation, and CIMP [9]. Of these, BRAF mutation is the most common alteration in all serrated polyp types, with a rate of more than $80 \%$ in serrated carcinomas $[6,9]$. Furthermore, $B R A F$ mutation, an important early event in the serrated pathway, is regarded as an indicator of poor prognosis [10].

The mitogen-activated protein (MAP) kinase pathway plays a central role in embryogenesis and in cell differentiation, proliferation and death. Extracellular signal regulated kinase 1/2 (ERK1/2) are important kinases in the MAP kinase pathway [11-13]. Therefore, activation of ERK1/2 could be considered a target factor related with CRC carcinogenesis through the serrated pathway [14]. The present study investigated the clinicopathologic outcomes of $B R A F$ mutation and ERK1/2 expression related with the serrated pathway to CRC and the possibility of their being used as prognostic indicators.

\section{METHODS}

We analyzed 65 formalin-fixed, paraffin-embedded samples of resected tissues taken from patients with CRC and well preserved at Chung-Ang University Hospital between February and December 2011. The medical records of patients enrolled in the study were retrospectively analyzed. Histologic diagnoses were classified in accordance with the World Health Organization criteria [15]. Pathologic staging was performed according to American Joint Committee on Cancer (AJCC) Cancer Staging Manual [16].

Dual-priming oligonucleotide (DPO)-based multiplex polymerase chain reaction (PCR) was performed using the Seeplex $B R A F$ ACE detection system (Seegene, Seoul, Korea) to detect $B R A F^{V 600 E}$ mutation. Two pathologists reviewed the slides with tissues stained by using hematoxylin \& eosin dyes and marked the area of CRC. The genomic DNA could be extracted from $5-\mu \mathrm{m}-$ thick paraffin sections by using the QIAamp DNA mini Kit (Qiagen, Chartsworth, CA, USA). The PCR reaction mixture contained $4 \mu \mathrm{L}$ of $5 \times B R A F$ primer, $3 \mu \mathrm{L}$ of extracted DNA $(10 \mathrm{ng} / \mu \mathrm{L})$, $3 \mu \mathrm{L}$ of 8 -methoxypsoralen solution ( $0.01 \%)$, and $10 \mu \mathrm{L}$ of $2 \times$ multiplex master mix (Seegene). After 15 minutes of incubation at $94^{\circ} \mathrm{C}$, amplification was performed in a GeneAmp PCR system 7500 (Applied Biosystems, Foster City, CA, USA) with 35 cycles of denaturation at $94^{\circ} \mathrm{C}$ for 30 seconds, annealing at $62^{\circ} \mathrm{C}$ for $30 \mathrm{sec}-$ onds, extension at $72^{\circ} \mathrm{C}$ for 60 seconds, and a final extension at $72^{\circ} \mathrm{C}$ for 10 minutes. The amplified PCR products were analyzed using the ScreenTape system (Lab901, Edinburgh, UK) (Fig. 1).

Immunohistochemical analyses were performed in the same blocks that were used for the analyses of $B R A F^{\mathrm{V} 600 \mathrm{E}}$ mutation. Sec-
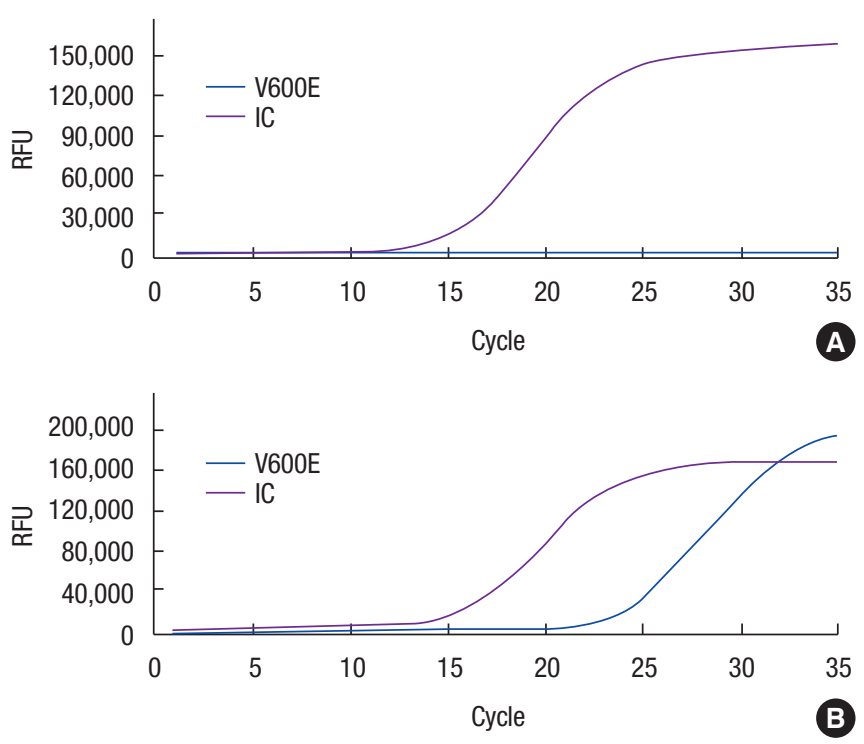

Fig. 1. Representative results from the dual-priming oligonucleotidebased multiplex polymerase chain reaction using the Seeplex BRAF ACE detection system (Seegene, Seoul, Korea) for the detection of $B R A F^{\mathrm{V} 600 \mathrm{E}}$ mutation. (A) The purple curve represents the internal control (IC). (B) The blue curve (V600E, right side) represents mutant probes. All of them have a cycle threshold value of less than 35 . RFU, relative fluorescence units.

tions ( 4 to $5 \mu \mathrm{m}$ thick) of paraffin-embedded samples were deparaffinized in xylene by using three changes of 5 minutes each and were then rehydrated in 90\%, 75\%, and 50\% absolute alcohol for 2 minutes each. Endogenous peroxidase was inactivated by incubation with $0.3 \%$ hydrogen peroxide in methanol for 10 minutes, was washed with $50-\mathrm{mM}$ tris buffered saline ( $\mathrm{pH} 7.5$ ), and was pretreated with normal goat serum for 30 minutes to reduce nonspecific reactions. Sections were incubated at room temperature for 2 hours with each primary antibody. The primary antibodies used were ERK1 (1:200; Epitomics, Burlingame, CA, USA) and ERK2 (1:150; Epitomics). Immunohistochemical staining was performed using a standard avidin-biotin complex method. 3-amino-9-ethylcarbazole (ACE) was used as a substrate, and Mayer's hematoxylin was used for counterstaining. Light microscopic evaluations of all immune-stained slides were performed by one experienced pathologist. Nuclear Staining in more than $15 \%$ of the tissue or cytoplasmic staining in more than $50 \%$ of the tissue was considered positive (Figs. 2, 3).

Correlations between the clinicopathologic factors and $B R A F$ or ERK1/2 were analyzed with the Pearson chi-square test and the Pearson correlation coefficient. Statistical analyses were performed using IBM SPSS Statistics ver. 19.0 (IBM Co., Armonk, NY, USA). A probability of 0.05 or less was considered statistically significant. 
Volume 31, Number 1, 2015

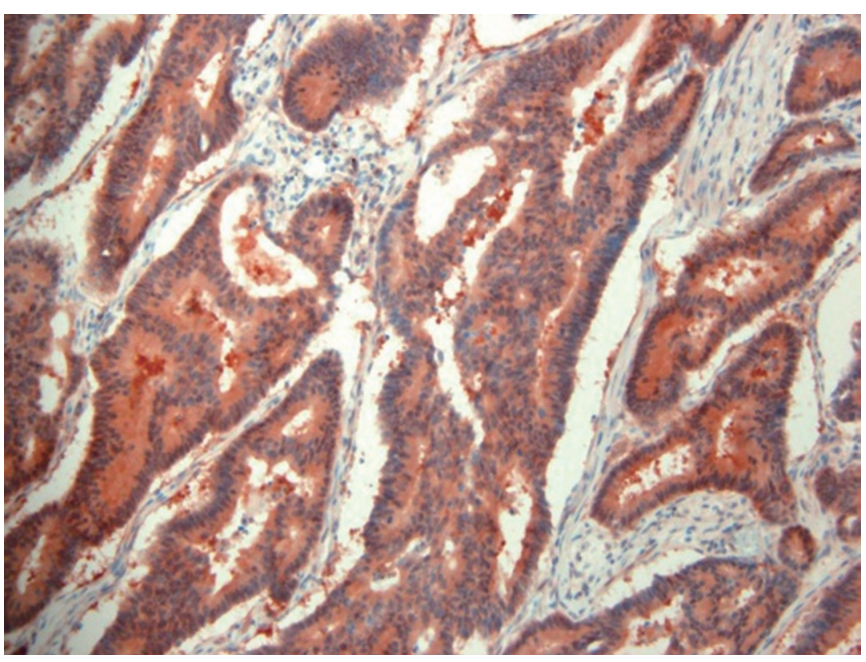

Fig. 2. Immunohistochemical staining for extracellular signal regulated kinase 1 . Strong cytoplasmic and nuclear immunoreactivity is seen in a colonic adenocarcinoma $(\times 200)$.

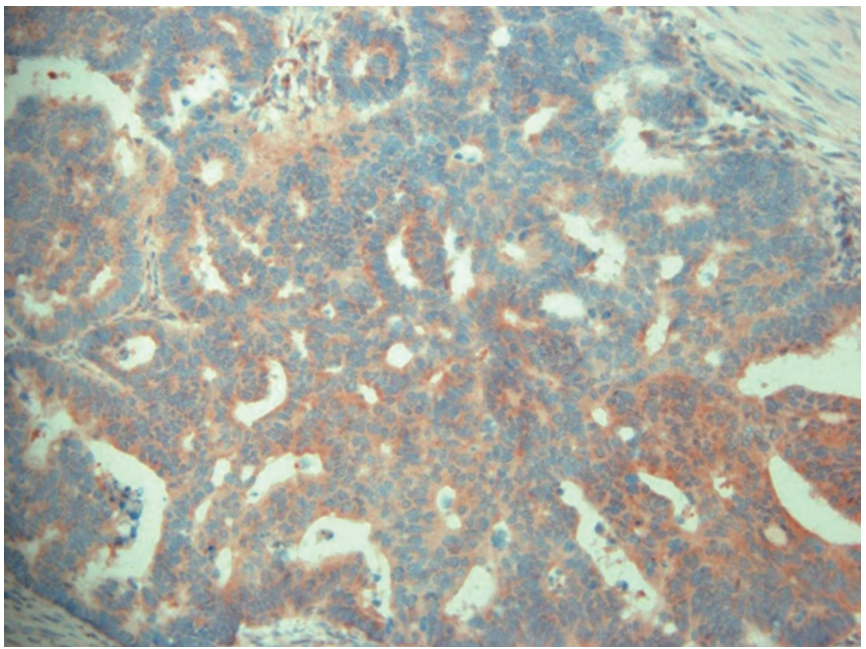

Fig. 3. Immunohistochemical staining for extracellular signal regulated kinase 2. Moderate cytoplasmic immunoreactivity is seen in a colonic adenocarcinoma $(\times 200)$.

\section{RESULTS}

The mean age of the 65 patients enrolled in this study was $67.2 \pm$ 10.8 years (range, $38-91$ years). Of these, 35 patients (53.8\%) were aged 67 and over. Male patients were 34 (52.3\%). In the histologic classification according to World Health Organization criteria, well-differentiated tumors were observed in 11 patients (16.9\%), moderately differentiated in $53(81.5 \%)$ and poorly differentiated in $1(1.5 \%)$. Tumor emboli were present in 21 patients (32.3\%). The TNM stages of the patients are presented in Table 1.

The overall frequency of $B R A F^{V 600 \mathrm{E}}$ mutations was $4.6 \%$ (3/65). A significant correlation existed between $B R A F^{\mathrm{V} 600 \mathrm{E}}$ mutation and
Table 1. Clinicopathologic characteristics of enrolled patients $(n=65)$

\begin{tabular}{lc}
\hline Variable & Value \\
\hline Age (yr) & $67.2 \pm 10.8$ \\
Mean \pm SD & $30(46.2)$ \\
$<67$ & $35(53.8)$ \\
$\geq 67$ & \\
Sex & $34(52.3)$ \\
Male & $31(47.7)$ \\
Female & \\
Tumor differentiation (WHO criteria) & $11(16.9)$ \\
Well & $53(81.5)$ \\
Moderately & $1(1.5)$ \\
Poorly & \\
Tumor emboli & $44(67.7)$ \\
Negative & $21(32.3)$ \\
Positive
\end{tabular}

Tumor invasion

$\begin{array}{cc}\text { T1 } & 6(9.2) \\ \text { T2 } & 11(16.9) \\ \text { T3 } & 48(73.8)\end{array}$

Lymph node metastasis

$\begin{array}{ll}\text { Absent } & 29(44.6) \\ \text { Present } & 36(55.4)\end{array}$

Stage (AJCC)

II

III

$16(24.6)$

$37(56.9)$

Values are presented as number (\%) unless otherwise indicated.

SD, standard deviation; WHO, World Health Organization; AJCC, American Joint Committee on Cancer.

histologic grade $(\mathrm{P}=0.026)$. All 3 patients with $B R A F^{\mathrm{V} 600 \mathrm{E}}$ mutation were aged 67 and over and presented with T3 CRC with lymph node metastasis (stage III), but correlations with age and CRC stage did not reach statistical significant (Table 2).

The immunostaining pattern for ERK1/2 was nuclear and cytoplasmic. Immunostaining for ERK1 was positive in $73.8 \%$ of the cases (48/65). A significant correlation existed between lymph node metastasis and ERK1 $(\mathrm{P}=0.049)$. CRC with lymph node metastasis had positive immunostaining in $83 \%$ of the cases (30/36). However, other clinicopathologic factors were not correlated with ERK1 (Table 3). Immunostaining for ERK2 was positive in $15.4 \%$ of the cases (10/65). A significant correlation existed between tumor emboli and ERK2 $(\mathrm{P}<0.05)$. Immunostaining for ERK2 was positive only in patients with T3 CRC $(\mathrm{P}=0.035)$. Also, lymph node metastasis and stage were positively correlated with Immunostaining for ERK2 ( $\mathrm{P}=0.017$ and $\mathrm{P}=0.02$, respectively) (Table 4 ). 
Table 2. Correlation between BRAF mutation and clinicopathologic characteristics $(\mathrm{n}=65)$

\begin{tabular}{|c|c|c|c|}
\hline \multirow{2}{*}{ Variable } & \multicolumn{2}{|c|}{ BRAF mutation } & \multirow{2}{*}{ P-value } \\
\hline & - & $+(\%)$ & \\
\hline Age (yr) & & & NS \\
\hline$<67$ & 30 & $0(0)$ & \\
\hline$\geq 67$ & 32 & $3(8.6)$ & \\
\hline Sex & & & NS \\
\hline Male & 33 & $1(2.9)$ & \\
\hline Female & 29 & $2(6.5)$ & \\
\hline Tumor differentiation (WHO criteria) & & & 0.026 \\
\hline Well & 11 & $0(0)$ & \\
\hline Moderately & 51 & $2(3.8)$ & \\
\hline Poorly & 0 & $1(100)$ & \\
\hline Tumor emboli & & & NS \\
\hline Negative & 43 & $1(2.3)$ & \\
\hline Positive & 19 & $2(9.5)$ & \\
\hline Tumor invasion & & & NS \\
\hline $\mathrm{T} 1$ & 6 & $0(0)$ & \\
\hline T2 & 11 & $0(0)$ & \\
\hline T3 & 45 & $3(6.3)$ & \\
\hline Lymph node metastasis & & & NS \\
\hline Absent & 29 & $0(0)$ & \\
\hline Present & 33 & $3(8.3)$ & \\
\hline Stage (AJCC) & & & NS \\
\hline I & 16 & $0(0)$ & \\
\hline$\|$ & 12 & $0(0)$ & \\
\hline III & 34 & $3(8.1)$ & \\
\hline Total & 62 & $3(4.6)$ & \\
\hline
\end{tabular}

Values are presented as number (\%).

NS, no statistical significance; WHO, World Health Organization criteria; AJCC, American Joint Committee on Cancer.

\section{DISCUSSION}

The BRAF (B-Raf proto-oncogene) encodes a serine/threonine kinase that plays an important role in intracellular signaling and cell growth and is a downstream effector of KRAS, which leads to epidermal growth factor receptor-independent activation of MAP kinase signaling pathways $[17,18]$. Much histologic research increasingly supports the colorectal carcinogenesis through the serrated pathway, which is linked with $B R A F$ mutation $[5-7,19]$. Furthermore, $B R A F$ mutation is associated with poor prognosis in metastatic CRC [10] and confers a worse prognosis to stages II and III colon cancer patients independently of disease stage and therapy [20, 21].

$B R A F$ mutations have been identified in various cancer cell
Table 3. Correlation between ERK1 expression and clinicopathologic characteristics $(n=65)$

\begin{tabular}{|c|c|c|c|}
\hline \multirow{2}{*}{ Variable } & \multicolumn{2}{|c|}{ ERK1 expression } & \multirow{2}{*}{ P-value } \\
\hline & - & $+(\%)$ & \\
\hline Age (yr) & & & NS \\
\hline$<67$ & 7 & $23(76.7)$ & \\
\hline$\geq 67$ & 10 & $25(71.4)$ & \\
\hline Sex & & & NS \\
\hline Male & 9 & $25(73.5)$ & \\
\hline Female & 8 & $23(74.2)$ & \\
\hline Tumor differentiation (WHO criteria) & & & NS \\
\hline Well & 2 & $9(81.8)$ & \\
\hline Moderately & 15 & $38(71.7)$ & \\
\hline Poorly & 0 & $1(100)$ & \\
\hline Tumor emboli & & & NS \\
\hline Negative & 13 & $31(70.5)$ & \\
\hline Positive & 4 & $17(81.0)$ & \\
\hline Tumor invasion & & & NS \\
\hline $\mathrm{T} 1$ & 4 & $2(33.3)$ & \\
\hline T2 & 3 & $8(72.7)$ & \\
\hline T3 & 10 & $38(79.2)$ & \\
\hline Lymph node metastasis & & & 0.049 \\
\hline Absent & 11 & $18(62.1)$ & \\
\hline Present & 6 & $30(83.3)$ & \\
\hline Stage (AJCC) & & & NS \\
\hline I & 7 & $9(56.3)$ & \\
\hline$\|$ & 4 & $8(66.7)$ & \\
\hline III & 6 & 31 (83.8) & \\
\hline Total & 17 & 48 (73.8) & \\
\hline
\end{tabular}

Values are presented as number (\%).

NS, no statistical significance; WHO, World Health Organization criteria; AJCC, American Joint Committee on Cancer.

lines, which include melanoma, CRC, glioma, lung cancer, sarcoma, ovarian carcinoma, breast cancer, and liver cancer [22]. The $B R A F$ gene sequence variant p. Val600Glu, often called V600E, is the main sequence variant in this gene that is associated with CRC $[22,23]$. Therefore, we performed DPO-based multiplex PCR to detect $B R A F^{\mathrm{V} 600 \mathrm{E}}$ mutation.

To now, most Western research has reported that $B R A F$ mutation occurred in about $10 \%-20 \%$ of CRC patients $[20,21,24,25]$, but the present study showed a lower prevalence of BRAF mutations, only $4.6 \%$. Other Korean studies also reported only $4.5 \%-$ $9.6 \%$ of $B R A F$ mutation in cases of CRC $[26,27]$. The lower prevalence of $B R A F$ mutations may be associated with racial and ethnic differences. In recent Japanese studies, the prevalence of $B R A F$ mutations also tended to be lower, $4.7 \%-6.7 \%[28,29]$. Further 
Table 4. Correlation between ERK2 expression and clinicopathologic characteristics $(n=65)$

\begin{tabular}{|c|c|c|c|}
\hline \multirow{2}{*}{ Variable } & \multicolumn{2}{|c|}{ ERK2 expression } & \multirow{2}{*}{ P-value } \\
\hline & - & $+(\%)$ & \\
\hline Age (yr) & & & NS \\
\hline$<67$ & 24 & $6(20.0)$ & \\
\hline$\geq 67$ & 31 & $4(11.4)$ & \\
\hline Sex & & & NS \\
\hline Male & 29 & $5(14.7)$ & \\
\hline Female & 26 & $5(16.1)$ & \\
\hline Tumor differentiation (WHO criteria) & & & NS \\
\hline Well & 11 & $0(0)$ & \\
\hline Moderately & 43 & $10(18.9)$ & \\
\hline Poorly & 1 & $0(0)$ & \\
\hline Tumor emboli & & & 0.042 \\
\hline Negative & 40 & $4(9.1)$ & \\
\hline Positive & 15 & $6(28.6)$ & \\
\hline Tumor invasion & & & 0.035 \\
\hline T1 & 6 & $0(0)$ & \\
\hline T2 & 11 & $0(0)$ & \\
\hline T3 & 38 & $10(20.8)$ & \\
\hline Lymph node metastasis & & & 0.017 \\
\hline Absent & 28 & $1(3.4)$ & \\
\hline Present & 27 & $9(25.0)$ & \\
\hline Stage (AJCC) & & & 0.020 \\
\hline I & 16 & $0(0)$ & \\
\hline$\|$ & 11 & $1(8.3)$ & \\
\hline III & 28 & $9(24.3)$ & \\
\hline Total & 55 & $10(15.4)$ & \\
\hline
\end{tabular}

Values are presented as number (\%).

NS, no statistical significance; WHO, World Health Organization criteria; AJCC, American Joint Committee on Cancer.

study about the association between BRAF mutation and life style or dietary habits, besides racial and ethnic differences, should be conducted in the future.

In the present study, all 3 patients with $B R A F$ mutation presented with T3 CRC with lymph node metastasis (stage III) showing moderately or poorly differentiated histology. These data suggest that $B R A F$ mutation could be considered as a poor prognostic marker for CRC. Several Asian reports suggested that tumors harboring $B R A F$ mutations had different clinicopathologic features, including older age, proximal site, tumor grade (especially for poorly differentiated or mucinous type), microsatellite instability high, and poor overall survival $[26,28]$. Although $B R A F$ mutation has prognostic value according to some reports $[10,26$, $28,29]$, a large multicenter study would be needed to evaluate the prognostic significance in Korean CRC patients because of the low prevalence of $B R A F$ mutations in Korean patients with CRC.

$B R A F$ mutation is a common genetic alteration found in research related to serrated polyps [5, 6]. BRAF mutations present in more than $50 \%$ of hyperplastic polyps, in about $80 \%$ of sessile serrated adenomas/polyps, and in about $60 \%$ of traditional serrated polyps [6]. These data are not much different from the Korean data, but the prevalence in Korea is slightly lower [30]. CRC in general develops through one of two independent molecular pathways that involve sequences of genomic and epigenomic alterations associated with pathologic and clinical features, the adenoma-carcinoma sequence in $70 \%-80 \%$ of the cases and the serrated pathway in the remaining 20\%-30\% [6]. BRAF-mutated CRC was observed in only $4.6 \%$ of the cases in the present study; this result indicates that various factors contribute to activating the MAP kinase signaling pathway in the serrated pathway to CRC. Previous publications described somatic molecular alterations, besides $B R A F$ mutation, that were associated with the serrated pathway; these include KRAS mutations, MLH1 methylation, MGMT methylation, and CIMP [31].

Various types of molecular markers have been developed to identify carcinogenesis of CRC through serrated pathways. Among them, the MAP kinase signaling pathway is a common mechanism of signal transduction in many cellular processes, such as proliferation, differentiation, development, stress response, and apoptosis [32]. ERK activation in the MAP kinase signaling pathway occurs in the majority of patients with primary colon cancer, and ERK nuclear expression is positively correlated with tumor stage [25]. The present study also found that ERK1/2 were significantly correlated with advanced CRC. Expression of ERK1/2 may possibly be associated with a more aggressive phenotype, such as tumor invasiveness.

Levidou et al. [25] used polyclonal antibody for ERK1/2 immunostaining, and positive nuclear immunostaining (staining in more than $15 \%$ of the tissue) occurred in about $50 \%$ of the cases and positive cytoplasmic immunostaining (staining in more than $50 \%$ of the tissue) occurred in about $70 \%$ of the cases. However, we used monoclonal antibody for both ERK1 and ERK2, and immunostaining for ERK1 and ERK2 was positively detected in $73.8 \%$ and $15.4 \%$ of the cases, respectively. Pathologic presentations were somewhat different between ERK1 and ERK2. However, no difference in clinicopathologic outcomes existed between nuclear and cytoplasmic immunostaining, which might have been due to the small sample size. A further study using multivariate and long-term survival analyses needs to be performed with a larger number of patients to improve the accuracy of prognostic predictions using ERK1/2.

The present study could not identify any clinicopathologic correlation between $B R A F$ mutation and ERK1/2 due to a low prevalence of $B R A F$ mutations. Levidou et al. [25] reported that expression of ERK1/2 was not correlated with the mutational status of the KRAS or the BRAF genes. Even now, the genetic nature of the 
constitutive activation of the RAS/RAF/MEK/ERK pathway in CRC without KRAS or BRAF mutation is not well known.

In conclusion, the incidence of $B R A F$ mutations was $4.6 \%$ in $\mathrm{Ko}-$ rean patients with CRC, and $B R A F$ mutation may be associated with advanced stage. ERK1 and ERK2 may be associated with a more aggressive type of CRC, which would indicate a poor prognosis. In the future, further study with a larger number of patients focusing on the prognostic and predictive role of the molecular markers associated with the serrated pathway to CRC is required.

\section{CONFLICT OF INTEREST}

No potential conflict of interest relevant to this article was reported.

\section{REFERENCES}

1. Fearon ER, Vogelstein B. A genetic model for colorectal tumorigenesis. Cell 1990;61:759-67.

2. Wang L, Patel U, Ghosh L, Chen HC, Banerjee S. Mutation in the $\mathrm{nm} 23$ gene is associated with metastasis in colorectal cancer. Cancer Res 1993;53:3652.

3. Aaltonen LA, Peltomaki P, Leach FS, Sistonen P, Pylkkanen L, Mecklin JP, et al. Clues to the pathogenesis of familial colorectal cancer. Science 1993;260:812-6.

4. Liu B, Nicolaides NC, Markowitz S, Willson JK, Parsons RE, Jen J, et al. Mismatch repair gene defects in sporadic colorectal cancers with microsatellite instability. Nat Genet 1995;9:48-55.

5. Yang S, Farraye FA, Mack C, Posnik O, O'Brien MJ. BRAF and KRAS Mutations in hyperplastic polyps and serrated adenomas of the colorectum: relationship to histology and CpG island methylation status. Am J Surg Pathol 2004;28:1452-9.

6. Rosty C, Parry S, Young JP. Serrated polyposis: an enigmatic model of colorectal cancer predisposition. Patholog Res Int 2011; 2011:157073.

7. Lash RH, Genta RM, Schuler CM. Sessile serrated adenomas: prevalence of dysplasia and carcinoma in 2139 patients. J Clin Pathol 2010;63:681-6.

8. Torlakovic EE, Gomez JD, Driman DK, Parfitt JR, Wang C, Benerjee $\mathrm{T}$, et al. Sessile serrated adenoma (SSA) vs. traditional serrated adenoma (TSA). Am J Surg Pathol 2008;32:21-9.

9. O’Brien MJ, Yang S, Mack C, Xu H, Huang CS, Mulcahy E, et al. Comparison of microsatellite instability, $\mathrm{CpG}$ island methylation phenotype, BRAF and KRAS status in serrated polyps and traditional adenomas indicates separate pathways to distinct colorectal carcinoma end points. Am J Surg Pathol 2006;30:1491-501.

10. Van Cutsem E, Kohne CH, Lang I, Folprecht G, Nowacki MP, Cascinu S, et al. Cetuximab plus irinotecan, fluorouracil, and leucovorin as first-line treatment for metastatic colorectal cancer: updated analysis of overall survival according to tumor KRAS and BRAF mutation status. J Clin Oncol 2011;29:2011-9.

11. Meloche S, Pouyssegur J. The ERK1/2 mitogen-activated protein kinase pathway as a master regulator of the G1- to S-phase transition. Oncogene 2007;26:3227-39.

12. Mercer K, Chiloeches A, Huser M, Kiernan M, Marais R, Pritchard C. ERK signalling and oncogene transformation are not impaired in cells lacking A-Raf. Oncogene 2002;21:347-55.

13. Pearson G, Robinson F, Beers Gibson T, Xu BE, Karandikar M, Berman K, et al. Mitogen-activated protein (MAP) kinase pathways: regulation and physiological functions. Endocr Rev 2001;22: 153-83.

14. Bongers G, Muniz LR, Pacer ME, Iuga AC, Thirunarayanan N, Slinger E, et al. A role for the epidermal growth factor receptor signaling in development of intestinal serrated polyps in mice and humans. Gastroenterology 2012;143:730-40.

15. Jass JR, Sobin LH, editors. Histological typing of intestinal tumours. In: World Health Organization. International histological classification of tumours. 2nd ed. Berlin: Springer; 1989.

16. Edge S, Byrd DR, Compton CC, Fritz AG, Greene FL, Trotti A, editors. AJCC cancer staging manual. 7th ed. New York: Springer; 2010.

17. Chan TL, Zhao W, Leung SY, Yuen ST; Cancer Genome Project. BRAF and KRAS mutations in colorectal hyperplastic polyps and serrated adenomas. Cancer Res 2003;63:4878-81.

18. Sclafani F, Gullo G, Sheahan K, Crown J. BRAF mutations in melanoma and colorectal cancer: a single oncogenic mutation with different tumour phenotypes and clinical implications. Crit Rev Oncol Hematol 2013;87:55-68.

19. Kambara T, Simms LA, Whitehall VL, Spring KJ, Wynter CV, Walsh MD, et al. BRAF mutation is associated with DNA methylation in serrated polyps and cancers of the colorectum. Gut 2004; 53:1137-44.

20. Farina-Sarasqueta A, van Lijnschoten G, Moerland E, Creemers GJ, Lemmens VE, Rutten HJ, et al. The BRAF V600E mutation is an independent prognostic factor for survival in stage II and stage III colon cancer patients. Ann Oncol 2010;21:2396-402.

21. Ogino S, Shima K, Meyerhardt JA, McCleary NJ, Ng K, Hollis D, et al. Predictive and prognostic roles of BRAF mutation in stage III colon cancer: results from intergroup trial CALGB 89803. Clin Cancer Res 2012;18:890-900.

22. Davies H, Bignell GR, Cox C, Stephens P, Edkins S, Clegg S, et al. Mutations of the BRAF gene in human cancer. Nature 2002;417: 949-54.

23. Qiu J, Compagnone M, Laibe S, Lagarde A, Goncalves A, Turrini O, et al. BRAF p.Val600Glu (V600E) somatic mutation is mainly associated with MSS phenotype in metastatic colorectal cancer. Cancer Genomics Proteomics 2011;8:15-8.

24. Di Nicolantonio F, Martini M, Molinari F, Sartore-Bianchi A, Arena S, Saletti P, et al. Wild-type BRAF is required for response to panitumumab or cetuximab in metastatic colorectal cancer. J Clin Oncol 2008;26:5705-12.

25. Levidou G, Saetta AA, Gigelou F, Karlou M, Papanastasiou P, Stamatelli A, et al. ERK/pERK expression and B-raf mutations in colon adenocarcinomas: correlation with clinicopathological char- 
acteristics. World J Surg Oncol 2012;10:47.

26. Kim B, Park SJ, Cheon JH, Kim TI, Kim WH, Hong SP. Clinical meaning of BRAF mutation in Korean patients with advanced colorectal cancer. World J Gastroenterol 2014;20:4370-6.

27. Lee S, Cho NY, Choi M, Yoo EJ, Kim JH, Kang GH. Clinicopathological features of $\mathrm{CpG}$ island methylator phenotype-positive colorectal cancer and its adverse prognosis in relation to KRAS/ BRAF mutation. Pathol Int 2008;58:104-13.

28. Nakanishi R, Harada J, Tuul M, Zhao Y, Ando K, Saeki H, et al. Prognostic relevance of KRAS and BRAF mutations in Japanese patients with colorectal cancer. Int J Clin Oncol 2013;18:1042-8.

29. Soeda H, Shimodaira H, Watanabe M, Suzuki T, Gamoh M, Mori
T, et al. Clinical usefulness of KRAS, BRAF, and PIK3CA mutations as predictive markers of cetuximab efficacy in irinotecanand oxaliplatin-refractory Japanese patients with metastatic colorectal cancer. Int J Clin Oncol 2013;18:670-7.

30. Kim KM, Lee EJ, Ha S, Kang SY, Jang KT, Park CK, et al. Molecular features of colorectal hyperplastic polyps and sessile serrated adenoma/polyps from Korea. Am J Surg Pathol 2011;35:1274-86.

31. Patai AV, Molnar B, Tulassay Z, Sipos F. Serrated pathway: alternative route to colorectal cancer. World J Gastroenterol 2013;19: 607-15.

32. Rubinfeld H, Seger R. The ERK cascade: a prototype of MAPK signaling. Mol Biotechnol 2005;31:151-74. 